\title{
Foot Controls: Riding the Pedal
}

\author{
Ralph L. Barnett ${ }^{*}$ \\ Mechanical and Aerospace Engineering, Illinois Institute of Technology, Chicago, and Chairman of the Board, Tri- \\ odyne Inc., Northbrook, IL, USA
}

\begin{abstract}
The two predominant scenarios for accidentally tripping a foot control are stepping into the foot control and onto the pedal, i.e., "stepping contact;" and keeping one foot on or just above the pedal at all times, i.e., "riding the pedal." This study shows that the various designs used to minimize "stepping contact" exacerbate inadvertent activation by "riding the pedal."
\end{abstract}

\section{INTRODUCTION}

Foot controls are used to activate machines in a variety of circumstances. A machine's productivity in the manual mode often requires that the operator's hands be utilized during the entire operational profile. A plethora of controls may require all of the operator's appendages. In situations where the hands can become entrapped, prudent safety management may require emergency stop foot switches or foot valves. Intervention systems for carpal tunnel syndrome arising from two-hand hostage controls may adopt foot controls. In all such cases there are periods where both hands may be exposed to point-of-operation hazards.

It is a universal admonition in machine design that controls be fashioned to minimize the probability of accidental activation. Tripping is the worry when foot controls are employed because operators seldom scrutinize the floor surface when they're working. This leads to inadvertent activation of the foot controls, which produces unexpected start-up of the machinery. This, of course, compromises the safety of both personnel and equipment and often destroys the work piece being processed. Operators who are misusing the machines are usually protected during random cycling by point-ofoperation guards or devices; maintenance personnel and bystanders are almost always at risk.

Old-fashioned foot controls (circa 1930) would typically consist of a foot pedal located at a fixed station and disposed about six inches above the floor. Activation forces of over sixty-five pounds were common and the associated pedal throw was about three inches. With the advent of ergonomics, operator comfort, performance and convenience were addressed and the modern foot control emerged [1-8].

Whereas the old-fashioned foot controls were practically immune to "stepping contact," modern foot controls are a safety nightmare. These devices, which are tethered to machines by electric cords or pneumatic hoses, are placed or migrate throughout the operator's workspace and constitute serious trip hazards. The pedals are located at an inch and a

*Address correspondence to this author at the Illinois Institute of Technology, Chicago, and Chairman of the Board, Triodyne Inc., Northbrook, IL, USA; E-mail: rbarnett@triodyne.com half above the floor. This distance makes the pedal particularly vulnerable to being stepped on since the normal walking gait brings the toe about two inches above the walking surface. Relatively speaking, the modern pedal is a "hair trigger" with a threshold force of about ten pounds and an associated activation throw in the neighborhood of $3 / 4$ inches.

In response to the safety shortcomings of the modern foot control under misuse conditions (absence of point-ofoperation safe-guarding), manufacturers have introduced a variety of concepts for minimizing inadvertent activation arising from "stepping contact." For example, top barrier guards, side shields, pedal locks, and front gates are used in various combinations. Unfortunately, as the intervention strategies become increasingly successful at preventing "stepping contact," the foot control becomes more prone to the really insidious problem of "riding the pedal."

\section{THE TEST PROGRAM}

Three foot control activation scenarios form the basis of our study:

\subsection{Riding the Pedal}

One foot is continually poised above or just touching the foot pedal until a machine stroke is required. The foot then depresses the foot pedal, eventually returning to its position above the pedal. It is never withdrawn from the foot control. "Riding the pedal" is analogous to hunters "keeping their finger on the trigger." Riding the pedal is the most prevalent cause of accidental activation of power presses. When power press operators keep their foot deployed over the pedal, accidental activation may occur during sneezing, reaching forward, slipping, and from foot fatigue or being bumped forward.

\subsection{Pivoting}

Starting with both feet on the floor, one foot is pivoted about the heel and swung into the foot control. It then depresses the foot pedal and swings back into its original position on the floor. "Riding the pedal" does not occur; furthermore, the active foot never lifts or shifts its heel. This strategy is usually available only with open-sided controls. Although side-shielded, it was feasible to use the pivot mode 
with the Schrader foot valve because of its exceptional width (6 inches).

\subsection{Reciprocation}

Starting with both feet on the floor, one foot is inserted into the foot control by a forward movement followed by a depression onto the pedal. This foot is then moved rearward into its original (starting) position. "Riding the pedal" does not occur. During reciprocation, the operator's weight is supported by the non-active foot. This operating mode may be used with either open-sided or side-shielded controls.

Our investigation began with the observation that:

The more difficult it is to step into and out of a foot control, the more likely it is that operators will "ride the pedal."

One method of quantifying "activity difficulty" is to measure the maximum stroke rate under speed provoking conditions. Accordingly, a test protocol was formulated for the pivoting mode and the reciprocating mode with the following characteristics:

Participants: Male and female senior engineering students. Only the results of the males are recorded in this study; the sample size for females was too small.

Goal: For each foot control candidate, the students tried their personal best to maximize the number of proper activation strokes in a thirty second period. This short time interval was selected to eliminate endurance effects which are not encountered in the workplace.

Position: Each foot control was fixed in location. The students operated the controls from a freestanding position.

Practice: One practice run was performed for each foot control candidate.

Fidelity: Strict adherence to the definitions of pivoting and reciprocation was enforced by fellow students.

Incentive: Striving for one's personal best score was influenced by the following factors:

- $\quad$ The students were proctored by the class professor.

- The test program was conducted as a contest with published results.

- $\quad$ Peer pressure

- Machismo

\section{TEST RESULTS}

Using the test protocol, stroke rates were determined for the twelve foot controls shown in Fig. (1). They are illustrated in descending order of the stroke rate obtained in the reciprocating mode. The first five controls can be activated in the pivoting and reciprocating modes and the associated stroke rates are listed for both. Foot control characteristics illustrated in Fig. (2) are tabulated in Fig. (1). A minimum force is recorded for each candidate that represents the force applied to the lip of the foot pedal which just activates the control. In 1980, the candidate foot controls 1, 2, 3, 4, 5, 7, 8, 10,11 , and 12 were tested one time by each of thirty-nine male students. Candidate 6 was tested in 1977; the test was repeated three times by each of fifteen male students. In 1984, candidate 9 was tested by seventeen male students who repeated the trial three times.

Foot controls are grouped below according to the safeguarding systems used to minimize accidental trip activation from "stepping contact."

\subsection{Top Guard}

Top guards preclude foot control activation from the rear and top. Candidates 1, 2, 3, and 4 are top-guarded controls. They may be activated and deactivated from both the front and sides using the reciprocating or pivoting scenarios. Further, they accommodate wide footwear. These utilitarian features also have safety overtones. First, they reduce fatigue by allowing the operator to alternate activation strategies. Second, foot removal is uninhibited leading to very rapid emergency stop commands. Finally, the foot cannot be blocked by a rolling cart, box or other obstruction to prevent deactivation. Power presses often have a continuous mode that requires constant depression of the foot pedal. The operator intercedes during an emergency by removing his foot from the control.

\subsection{Top Guard and Side Shields}

These safeguards are used by candidates 5, 6 and 7. Access to the foot pedal is blocked on the sides which helps reduce "stepping contact." On the other hand, the side shields inhibit somewhat the movement of the foot during reciprocation. Unlike the open-sided candidates, the pivoting mode is usually not available for relief of fatigue from the reciprocating action. Riding the pedal provides the only feasible respite.

\subsection{Pedal Lock}

Candidates 8 and 9 are constructed with a pedal latch that will lock the pedal unless the foot is fully inserted into the foot control and pushed rearward against a vertical plate. After unlatching in this manner, the pedal is depressed to activate the control. Activation of this foot control is generally perceived as a two-step process: unlatch and depress. As it turns out, however, experienced operators hit the latch and pedal in a single motion. Inadvertent partial insertion of the foot will not trip this control.

\subsection{Lift Gate}

Candidates 9, 10 and 11 are protected in part by front gates which must first be lifted by the toe to gain access to the foot pedal, which in turn must be depressed to activate the foot control. This two-step procedure inhibits both normal and accidental activation by "stepping contact." The gate is effective in minimizing inadvertent intrusion; it does not, however, eliminate the problem. The lower edge of the front flap has a ski nose to help "the camel get his nose under the tent." Striking the ski nose hard with a flat toe shoe will almost always defeat the liftable gate and allow a one-motion activation. Candidate 9 combines the liftable gate with a pedal lock. Theoretically, activation is a three-step process; lift the gate, unlatch the lock and depress the pedal. As a practical matter, the ski nose enables the process to be accomplished using a single forceful motion. 


\begin{tabular}{|c|c|c|c|c|c|c|}
\hline $\begin{array}{l}\text { Foot } \\
\text { Controls }\end{array}$ & $\begin{array}{l}\text { Linemaster } \\
\text { Clipper } \\
\text { No. } 632-\mathrm{S} \\
\end{array}$ & Rees & $\begin{array}{c}\text { Square D } \\
\text { Type AW2 }\end{array}$ & 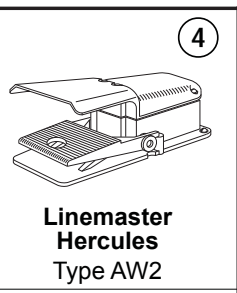 & Schrader & 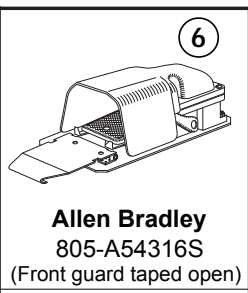 \\
\hline Reciprocating & Avg. $\quad 48.72$ & Avg. $\quad 48.36$ & Avg. $\quad 47.66$ & Avg. $\quad 46.69$ & Avg. $\quad 46.44$ & Avg. $\quad 46.30$ \\
\hline Strokes/30 sec. & $\begin{array}{l}\text { St'd Dev. } 8.95 \\
n=39\end{array}$ & $\begin{array}{l}\text { St'd Dev. } 10.40 \\
n=39\end{array}$ & $\begin{array}{l}\text { St'd Dev. } 12.59 \\
n=39\end{array}$ & $\begin{array}{l}\text { St'd Dev. } 7.73 \\
n=39\end{array}$ & $\begin{array}{l}\text { St'd Dev. } 8.41 \\
n=39\end{array}$ & $\begin{array}{l}\text { St'd Dev. } 9.58 \\
n=45\end{array}$ \\
\hline Pivoting & Avg. $\quad 47.06$ & Avg. $\quad 44.89$ & Avg. $\quad 42.03$ & Avg. $\quad 43.86$ & Avg. $\quad 45.75$ & \\
\hline Strokes/30 sec. & $\begin{array}{l}\text { St'd Dev. } 8.90 \\
n=39\end{array}$ & $\begin{array}{l}\text { St'd Dev. } 8.58 \\
n=39\end{array}$ & $\begin{array}{l}\text { St'd Dev. } 11.70 \\
n=39\end{array}$ & $\begin{array}{l}\text { St'd Dev. } 7.91 \\
n=39\end{array}$ & $\begin{array}{l}\text { St'd Dev. } 8.63 \\
n=39\end{array}$ & \\
\hline $\begin{array}{r}\text { Characteristics } \\
\text { Height: } \\
\text { Width: } \\
\text { Min. Force: } \\
\text { Throw: }\end{array}$ & $\begin{array}{l}3.0 \mathrm{in.} \\
\text { Open Sides } \\
7.0 \mathrm{lb} \\
0.375 \mathrm{in} .\end{array}$ & $\begin{array}{l}3.0 \text { in. } \\
\text { Open Sides } \\
12.0 \mathrm{lb} \\
0.5 \mathrm{in} .\end{array}$ & $\begin{array}{l}2.625 \text { in. } \\
\text { Open Sides } \\
5.0 \mathrm{lb} \\
0.5 \mathrm{in} .\end{array}$ & $\begin{array}{l}2.625 \text { in. } \\
\text { Open Sides } \\
7.5 \mathrm{lb} \\
0.75 \mathrm{in} .\end{array}$ & $\begin{array}{l}3.5 \mathrm{in} . \\
6.0 \mathrm{in} . \\
7.5 \mathrm{lb} \\
0.625 \mathrm{in} .\end{array}$ & $\begin{array}{l}2.75 \mathrm{in} . \\
5.625 \mathrm{in} . \\
8.0 \mathrm{lb} \\
1.0 \mathrm{in} .\end{array}$ \\
\hline $\begin{array}{l}\text { Foot } \\
\text { Controls }\end{array}$ & $\begin{array}{c}\text { Rees } \\
04937-000\end{array}$ & $\begin{array}{c}\text { Linemaster } \\
\text { Hercules } \\
511-\mathrm{B} 2 \\
\text { (Pedal Latch) }\end{array}$ & $\begin{array}{c}\text { Linemaster } \\
\text { Hercules } \\
511-B 2 G \\
\text { (Pedal Latch and Gate) }\end{array}$ & $\begin{array}{l}\text { Minster } \\
\text { Type ELL }\end{array}$ & $\begin{array}{c}\text { Square D } \\
\text { AW-117 }\end{array}$ & $\begin{array}{l}\text { Allen Bradley } \\
\text { 805-A54316S }\end{array}$ \\
\hline Reciprocating & Avg. $\quad 44.69$ & Avg. $\quad 36.66$ & Avg. & Avg. $\quad 28.86$ & Avg. $\quad 25.50$ & Avg. $\quad 16.94$ \\
\hline Strokes/30 sec. & $\begin{array}{l}\text { St'd Dev. } 10.29 \\
n=39\end{array}$ & $\begin{array}{l}\text { St'd Dev. } 6.97 \\
n=39\end{array}$ & $\begin{array}{l}\text { St'd Dev. } 6.23 \\
n=51\end{array}$ & $\begin{array}{l}\text { St'd Dev. } 6.02 \\
n=39\end{array}$ & $\begin{array}{l}\text { St'd Dev. } 4.61 \\
n=39\end{array}$ & $\begin{array}{l}\text { St'd Dev. } \\
\mathrm{n}=39\end{array}$ \\
\hline $\begin{array}{l}\text { Pivoting } \\
\text { Strokes/30 sec. }\end{array}$ & 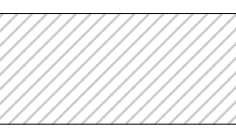 & 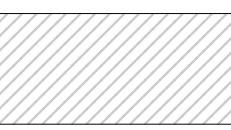 & 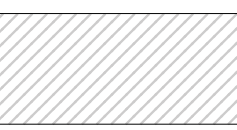 & 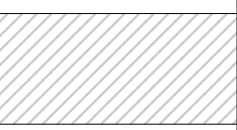 & 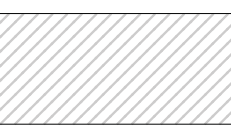 & 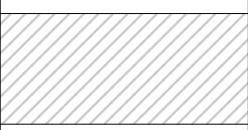 \\
\hline $\begin{array}{r}\text { Characteristics } \\
\text { Height: } \\
\text { Width: } \\
\text { Min. Force: } \\
\text { Throw: }\end{array}$ & $\begin{array}{l}3.5 \text { in. } \\
5.25 \mathrm{in} . \\
9.75 \mathrm{lb} \\
0.75 \mathrm{in} .\end{array}$ & $\begin{array}{l}2.75 \mathrm{in} . \\
5.50 \mathrm{in} . \\
13.0 \mathrm{lb} \\
0.875 \mathrm{in} .\end{array}$ & $\begin{array}{l}2.75 \mathrm{in} . \\
5.50 \mathrm{in} . \\
13.0 \mathrm{lb} \\
0.875 \mathrm{in} .\end{array}$ & $\begin{array}{l}2.75 \mathrm{in} . \\
5.25 \mathrm{in} . \\
9.5 \mathrm{lb} \\
0.5 \mathrm{in} .\end{array}$ & $\begin{array}{l}2.875 \mathrm{in} . \\
4.875 \mathrm{in} . \\
10.0 \mathrm{lb} \\
0.375 \mathrm{in} .\end{array}$ & $\begin{array}{l}2.75 \mathrm{in} . \\
5.625 \mathrm{in} . \\
8.0 \mathrm{lb} \\
1.0 \mathrm{in} .\end{array}$ \\
\hline
\end{tabular}

Fig. (1). Foot control: Stroke rates and characteristics (n... number of tests).

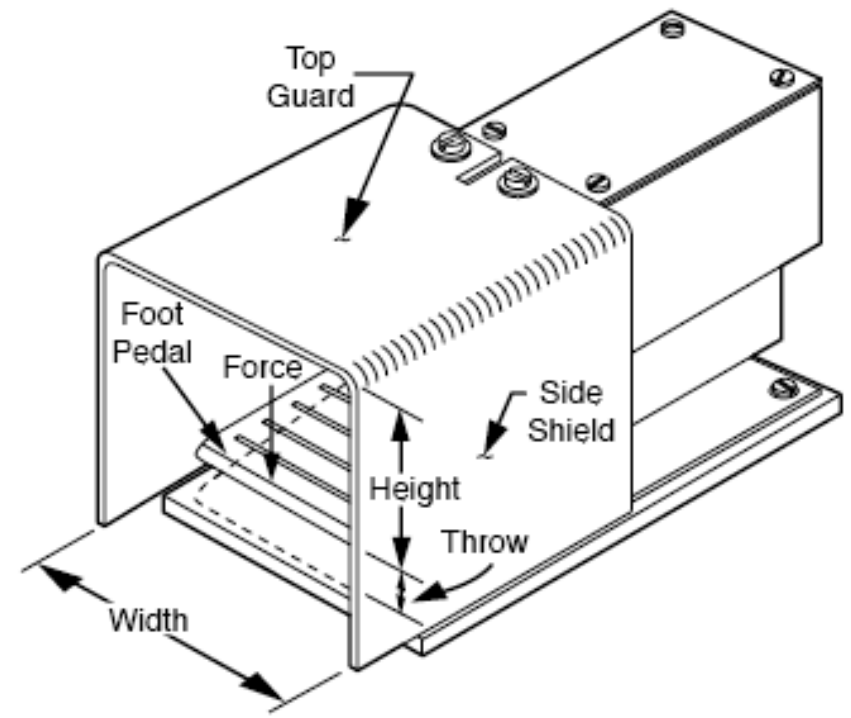

Fig. (2). Foot control characteristics.

\subsection{The Drawbridge Flap}

Foot control candidate 12 virtually eliminates "stepping contact." Here, a flap is hinged along the bottom and a spring constantly urges the drawbridge-type door to its vertical deployed position. Any force applied to the face of the flap closes it tighter. On the other hand, the control is relatively difficult to use. The flap is opened by dragging its upper edge backward with the sole of the shoe. The operator then inserts the foot, which is holding the flap open, and depresses the pedal to activate the control. The operator's weight is supported on one leg during this process. Proper deactivation of the switch requires the complete removal of the foot, which should then be placed on the floor allowing the flap to close. Avoiding continual reopening of the flap requires that the door be continuously held open against its spring closure force. Safety is not promoted by the constant application of a downward force in the neighborhood of the control pedal. Observe that candidate 6 is obtained by taping the flap open on candidate 12 . An almost three-fold increase in the stroke rates follows. 


\section{CONCLUSIONS}

- The twelve foot controls illustrated in Fig. (1) are arranged in decreasing order of their average stroke rate which is expressed as strokes $/ 30 \mathrm{sec}$. The sample size is indicated for each test series.

- With respect to the reciprocating activation mode, there are no statistical differences in the average number of strokes/30 sec among foot control candidates 1 through 7 within a $5 \%$ level of significance.

- $\quad$ The rankings of the foot controls 8 through 12 based on their average reciprocating strokes/30 sec are unique. Within a $5 \%$ level of significance, each of these foot controls differs from its neighbors.

- Only foot control candidates 1 through 5 are capable of activation in the pivoting mode. At the 95\% confidence level, there are no statistical differences among their average strokes/30 sec. This is a surprising result for candidate 5; this Shrader foot valve is sideshielded.

- The reciprocating mode is slightly more efficient than the pivoting mode.

- The open-sided models allow operators to deal with fatigue and discomfort by switching between two almost equally efficient activation strategies; pivoting and reciprocating. The side-shielded candidates offer only "riding the pedal" as an alternate activation method.

- $\quad$ The motivation to "ride the pedal" increases as one progresses from model 1 through model 12 in Fig. (1). Stroke rate decreases to a third. The more difficult it is to step into and out of a foot control, the more likely it is that operators will "ride the pedal."

- As one progresses from foot control candidate 1 through 12, the models pose a decreasing likelihood of an accidental "stepping contact." The harder it is to activate a control advertently, the harder it is to trip it inadvertently. The speed-provoked rate is observed to decrease as one progresses from model 1 through model 12 in Fig. (1).

- Conclusion 4.8 may be partially corroborated by simple geometric and functional observations. If candidates 10 and 11 are removed from the set, it is clear that increasingly severe foot insertion obstacles are being incorporated into the foot controls as one advances through Fig. (1). Even the extra wide Schrader shows up as the best of the three side-shielded models (5, 6 and 7). Candidates 10 and 11 cannot be ranked by qualitative observations; the actual detailed gate design plays an important role.

- The resistance to accidental "stepping contact" is inversely related to the propensity for "riding the pedal."

- The proper selection of a foot control is not straightforward. It involves many considerations including knowledge of operator movement in the work space, steadiness requirements for part insertion, the use of point-of-operation safeguarding, technology transfer, maximum or continuous stroke rate of the controlled machine and the various anticipated uses of the foot control on multi-mode machinery.

\section{REFERENCES}

[1] Corlett EN, Bishop RP. Foot pedal forces for seated operators. Ergonomics 1975; 18(6): 687-92.

[2] Kroemer KHE. Foot operation of controls. Ergonomics 1971; 12(3): 333-61.

[3] Trombley DJ. Experimental determination of an optimal foot pedal design [report]. Lubbock (TX): Central Library Texas, Technological College; 1966.

[4] Siemens Schuckertwerke AG. Kräfte an fussbetätigen bedienteilen. (Forces on foot-operated devices). [Siemens Report ZW/LFW1] Mitteilung aus den arbeitswissenschaft lichen Labor; 1965.

[5] Ayoub MM, Trombley DJ. Experimental determination of an optimal foot pedal design. J Indus Eng 1967; 18: 550-9.

[6] Docter HJ. The ergonomic aspects of working with the pedals in industry. Tijdschr soc Geneesk 1966; 44(16): 628-36. Section 17 in Excerpta Med 1967; 13: 280.

[7] Docter HJ. Ergonomic aspects of operating pedals in industry. Tijdschr Soc Geneesk 1966; 44(17): 666-71. Section 17 in Excerpta Med 1967 Feb; 13: 153.

[8] Barnes RM, Hardaway H, Podosky O. Which pedal is best? Factory Manage Maintenance 1942; 100(1): 98-9. 